Marquette University

e-Publications@Marquette

Psychology Faculty Research and Publications

Psychology, Department of

9-1-2007

\title{
Measuring the Discrepancy Between Current and Ideal Spiritual and Religious Functioning in Problem Drinkers
}

Stephen M. Saunders

Marquette University, stephen.saunders@marquette.edu

Valerie J. Lucas

Marquette University

Lesley Kuras

Saint Louis University

Accepted version. Psychology of Addictive Behaviors, Vol. 21, No. 3 (September 2007): 404-408. DOI. (C) 2019 American Psychological Association. Used with permission. 


\section{Marquette University}

\section{e-Publications@Marquette}

\section{Psychology Faculty Research and Publications/College of Arts and Sciences}

This paper is NOT THE PUBLISHED VERSION; but the author's final, peer-reviewed manuscript. The published version may be accessed by following the link in the citation below.

Psychology of Addictive Behaviors, Vol. 21, No. 3 (Sept 2007): 404-408. DOI. This article is (C) American Psychological Association and permission has been granted for this version to appear in ePublications@Marquette. American Psychological Association does not grant permission for this article to be further copied/distributed or hosted elsewhere without the express permission from American Psychological Association.

\section{Measuring the discrepancy between current and ideal spiritual and religious functioning in problem drinkers.}

Stephen M. Saunders

Marquette University, Milwaukee, WI

Valerie Lucas

Marquette University, Milwaukee, WI

Lesley Kuras

St. Louis University, Saint Louis University

\section{Abstract}

The idea that spiritual and religious functioning (SRF) is associated with alcohol misuse is generally supported, but problems with typical research methods limit the utility of findings. Problems in SRF were conceptualized as discrepancies between current and ideal SRF. Two separate studies were conducted to develop and evaluate a scale to measure the subjective importance and adequacy of aspects of SRF that seem to be associated with alcohol problems. The 1st study suggested that a questionnaire developed to evaluate self-reported ratings of current and ideal SRF is both internally consistent and temporally stable. In the 2 nd study, the questionnaire was 
administered to persons seeking treatment for alcohol problems and persons who indicated that they had never sought treatment for an alcohol problem. Results indicate that those with a drinking problem were more likely to report substantial discrepancies between current and ideal SRF, supporting the validity of the measure as an indicator of problems in SRF. The usefulness of this method for treatment and research is discussed.

\section{Keywords}

religiousness, spirituality, alcohol misuse, spiritual discrepancy

\section{Introduction}

Research indicates that there is a negative association between spiritual and religious thoughts, feelings, and behaviors (i.e., spiritual and religious functioning, or SRF) and alcohol use (e.g., Miller, 1999). The association has been found with both nonproblematic alcohol consumption (e.g., Albrecht, Amey, \& Miller, 1996; Engs, Hanson, \& Diebold, 1996) and alcohol misuse (e.g., Hardesty \& Kirby, 1995). Two large-scale surveys have reported, for example, that measures of religiousness were inversely related to drinking problems (Kendler, Gardner, \& Prescott, 1997; Single, Brewster, MacNeil, Hatcher, \& Trainor, 1995).

The treatment of alcohol problems has long been associated with spirituality and religiousness (cf. Gorsuch, 1993; Miller, 1997). For example, Alcoholics Anonymous explicitly prescribes improving one's spiritual life to promote sobriety (Emrick, Tonigan, Montgomery, \& Little, 1993). Studies have found that increasing one's spirituality or religious activity level is associated with recovery from alcohol-related problems (e.g., Kaskutas, Turk, Bond, \& Weisner, 2003) and that religious involvement increases over the course of successful treatment and ongoing recovery (e.g., Pardini, Plante, Sherman, \& Stump, 2000). Experimental studies also suggest that spiritually oriented programs are effective in reducing alcohol problems (e.g., Montgomery, Miller, \& Tonigan 1995). For example, a large clinical trial found that treatment designed to enhance benefit from 12-step programs was as effective as cognitive therapy and an intervention intended to enhance motivation to quit (Project MATCH Research Group, 1997).

\section{Conceptualizing SRF}

Spirituality comprises the thoughts, feelings, and behaviors of an individual that entail concern about, a search for, or a striving for understanding and relatedness to something transcendent or beyond the corporeal world (cf. Hill \& Pargament, 2003; Miller \& Thoresen, 2003). For many but not all individuals, the transcendent refers to a higher power or God. Religiousness comprises spiritual thoughts, feelings, and behaviors that are specifically related to a formally organized and identifiable religion. Spirituality is an idiographic aspect of the person that may be found outside of religious traditions and institutions, whereas religiousness is an expression of spirituality conducted within an identifiable community or belief system that prescribes, supports, sanctions, and validates it.

The measurement of SRF (or problems with SRF) has been challenging. Many aspects of psychological functioning can be measured objectively by comparison to a standardized norm. SRF is a subjective phenomenon, however. There are not and probably cannot be preferred levels or normative standards. Likewise, impairment of SRF probably cannot be judged or rated by objective standards. People evaluate their SRF subjectively and idiosyncratically, perhaps by comparison to some ideal derived from prior experience and their perception of social norms.

Problems with SRF should therefore be evaluated in terms of personal importance and adequacy, which are subjective phenomena (and which are conceptually related). If SRF is rated by a person as important, then its adequacy becomes a critical issue. In contrast, if one is indifferent towards SRF, then SRF probably should not be rated or regarded by others as inadequate. In other words, only the individual can determine whether his or her 
SRF is satisfactory or adequate and that rating will be related to that person's ratings of the importance of SRF. Thus, for example, individuals who readily and frequently engage in religious and spiritual behaviors may consider their SRF to be inadequate and unsatisfactory, whereas other people who never engage in either religious or spiritual activities may consider their SRF to be adequate and entirely satisfactory. Subjective ratings of importance and adequacy should be taken into account when evaluating SRF, but they are usually not. Most frequently, SRF is contrasted to normative data (e.g., Bufford, Paloutzian, \& Ellison, 1991), or different groups' engagement in spiritual or religious behavior is contrasted (e.g., Kendler et al., 1997).

\section{Essential Aspects of SRF in Alcohol Misuse}

Research suggests that the aspects of SRF most likely associated with alcohol misuse are the promotion of relatively healthy behaviors and feelings of connectedness.

\section{Healthy Behaviors}

Relatively high levels of spiritual and religious activities, such as participating in collective spiritual or religious services, praying or meditating, and reading spiritual material, are associated with less risk for alcohol misuse. These activities are associated with attitudes that contradict alcohol misuse and that promote positive emotions (Chatters, 2000) and an optimistic explanatory style (Sethi \& Seligman, 1993). In contrast, alcohol misuse may generate feelings of guilt that lead to disengagement from religious behaviors and greater dissatisfaction with SRF.

\section{Connectedness}

SRF-related behaviors are typically explicitly designed or intended to enhance feelings of being connected to God or a higher power and a sense of connectedness or community with other people. This is exemplified in religious practices that, perhaps universally, entail affiliative behaviors and a striving for greater closeness to a higher power (e.g., God or nature). SRF-related behaviors enhance social support, which allows corrective emotional experiences (Pargament \& Mahoney, 2002) and alleviates stress (Powell, Shahabi, \& Thoresen, 2003). These, in turn, may lessen the motivation to consume alcohol.

\section{The Present Study}

Two separate studies were conducted to develop and evaluate a scale to measure the subjective importance and adequacy of aspects of SRF that seem to be associated with alcohol problems. The first study entailed development of the measure, especially evaluating its psychometric properties. The second study evaluated whether persons seeking treatment for a drinking problem were more likely to report greater dissatisfaction with their SRF. Both studies were approved by the first author's institutional research review board overseeing the protection of human subjects.

\section{Study 1}

Study 1 reports the development and psychometric properties of the SRF Discrepancies Scales (SRF-DS), which are intended to rate respondents' subjective sense of satisfaction with SRF. Discrepancies were conceptualized as the difference between participants' ratings of their current SRF and their ideal SRF. The SRF-DS were administered to subjects to determine their internal consistency and test-retest reliability.

\section{Method}

\section{Participants}

Undergraduate students (43 men and 101 women) from a private Midwestern university were recruited from undergraduate psychology classes (the gender imbalance reflects the gender composition of most psychology courses at the school). On average, participants were 19.2 years old $(S D=1.4)$. Racial composition was 124 Caucasians, 3 African Americans, 2 Hispanics, 3 Asian Americans, and 10 who identified themselves as mixed 
race ( 2 participants did not indicate their race). Participants $(n=86)$ who completed the questionnaires a second time were included in the test-retest analyses.

\section{Materials}

The SRF-DS comprises five scales that assess three categories of SRF: satisfaction with SRF, feelings of connectedness or belonging, and SRF-related behaviors. Each scale comprises two subscales, Current and Ideal. On the Current subscales, participants indicated "how often you do something or experience something or how much you agree with a statement currently." For the Ideal subscales, participants responded to similar items indicating "how often you would do or experience something or would agree with a statement if things were the way you wanted." Items were identical except that verb tenses were changed to reflect current versus ideal states (e.g., "I feel" became "I would feel").

\section{SRF general satisfaction}

Two 10-item scales were derived from the Spirituality Well-Being Scale (Ellison \& Smith, 1991), which assesses subjective well-being and satisfaction related to religious and spiritual matters. The Religious Well-Being Scale (RWB) evaluates one's relationship with God, whereas the Existential Well-Being Scale (EWB) evaluates sense of purpose and life satisfaction. Statements (e.g., "I feel that life is a positive experience") are rated from strongly disagree to strongly agree. Prior research suggests that the scales have good internal consistency and testretest reliability and that higher scores indicate greater well-being.

\section{Connectedness}

The Connectedness to God Scale (CG) comprised five items selected from the Daily Spiritual Experiences Scale (Underwood, 1999). Items asked about feeling God's presence, guidance, and love; asking God for help; and feeling connected to God. The Connectedness to Others Scale (CO) contained six items from the Daily Spiritual Experiences Scale or other measures (Idler et al., 2003; Krause, 1999) that asked about interest, concern, and love for others in one's worship community. How often each event was experienced was rated from never to many times a day, and higher scores indicated greater feelings of connectedness to God and others.

\section{Spiritual and religious behaviors}

Six items derived from other instruments (cf. Fetzer Institute, 1999) constituted the SRF-Related Behaviors Scale (SRFB). Four items reflected private practices ("praying," "meditating," "listening to or watching spiritual or religious programs," and "reading religious or spiritual material"). Two items reflected public practices, including attending religious services and participating in other activities at a place of worship. Participants indicated how often they engaged in these behaviors on an 8-point scale ranging from never to several times a day. Higher scores indicated greater engagement in these activities.

\section{Procedure}

Questionnaires were completed anonymously; test-retest questionnaires were matched using unique identification codes. Most participants completed the packet of questionnaires twice within a 2-week period (range of time between administrations was 7 days to 11 days).

\section{Results}

As shown in Table 1, the current and ideal versions of the SRF-DS have sufficient internal reliability. Coefficient alphas ranged from .74 to .99 . Test-retest reliability was computed as the correlation between the scale scores at separate times, and $r$ ranged from .71 to .96 (see Table 1).

Table 1. Internal Consistencies and Test-Retest Reliabilities of Spiritual and Religious Functioning Scales 


\begin{tabular}{|l|l|l|l|l|}
\hline Scale & Current & Ideal & Current & Ideal \\
\hline Religious Well-Being & .97 & .99 & .93 & .82 \\
\hline Existential Well-Being & .90 & .94 & .80 & .71 \\
\hline Connectedness to God & .94 & .96 & .94 & .94 \\
\hline Connectedness to Others & .88 & .93 & .85 & .86 \\
\hline Spiritual and Religious & & & & \\
\hline Functioning-Related Behaviors & .74 & .85 & .96 & .92 \\
\hline
\end{tabular}

\section{Study 2}

The SRF-DS were administered to persons seeking treatment for an alcohol use problem and other adults who had never sought such treatment in order to test the hypothesis that the former would have relatively greater discrepancies between their current and ideal spiritual and religious functioning than the latter.

\section{Method}

\section{Participants}

The problem drinkers group included 80 adults with a mean age of 38.3 years $(S D=10.6)$ and mean years of education of $13.3(S D=2.2)$. They consisted of 22 women and 58 men; there were 69 Caucasians, 5 African Americans, 4 Hispanics, 1 Native American, and 1 who endorsed "other." The controls group comprised 106 adults randomly selected from the phone directory of a private Midwestern university. Their mean age was 41.4 years $(S D=12.7)$, and their mean education was 17.5 years $(S D=3.2)$. They included 56 women and 50 men, 91 Caucasians, 5 African Americans, 3 Hispanics, 3 Asian Americans, and 4 who endorsed "other." Problem drinkers and controls were significantly different in gender only.

\section{Measures}

The SRF-DS were completed by participants. Discrepancy scores were calculated as the difference between scores on the current and ideal functioning subscales. A brief demographic questionnaire was also administered.

\section{Procedure}

Both groups completed the SRF-DS via self-report. Problem drinkers were recruited from outpatient alcohol treatment centers in the Midwest within the first week of beginning treatment; all completed the study before the end of the second week. Inclusion criteria included being 21-75 years of age, inclusive, and identifying oneself as having a drinking problem. Controls were randomly selected from a campus directory. Inclusion criteria included being 21-75 years of age. Controls were asked whether they were or had ever been in treatment for an alcohol or drug problem; respondents who responded affirmatively were excluded from the study. Four potential controls were eliminated due to prior alcohol treatment, and three returned incomplete surveys. Thus, of 288 surveys sent out, useable surveys were returned by 104 adults (36.1\%).

\section{Results}

\section{Current Versus Ideal SRF Ratings: Within-Group Comparisons}

Average current and ideal SRF-DS scores of problem drinkers and controls are shown in Table 2. Multiple pairedsamples $t$ tests based on directional predictions (i.e., that ideal scores would be greater than current scores) were conducted, so that the Bonferroni correction for one-tailed tests resulted in an alpha level of .0067 $(.10 / 15)$ to determine statistical significance. Paired-samples $t$ tests were conducted for participants within the two groups, and there was a significant difference between current and ideal SRF scores for both groups on all

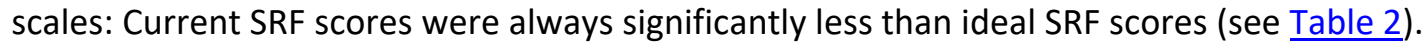

Table 2. Spiritual and Religious Functioning Scores of Problem Drinkers and Controls 


\begin{tabular}{|c|c|c|c|c|c|c|c|c|c|c|c|c|c|c|c|c|c|c|c|}
\hline & $\begin{array}{l}\text { All } \\
\text { participants }\end{array}$ & & & & & $\begin{array}{l}\text { Problem } \\
\text { Drinkers }\end{array}$ & & & & & & & Controls & & & & & & \\
\hline & Current & & Ideal & & & Current & & Ideal & & Discrepancy & & & Current & & Ideal & & Discrepancy & & \\
\hline Scale & M & SD & M & SD & $t(185)$ & M & SD & M & SD & M & SD & $t(79)$ & M & SD & M & SD & M & SD & $\mathrm{t}(105)$ \\
\hline $\begin{array}{l}\text { Religious Well- } \\
\text { Being }\end{array}$ & 40.2 & 15.1 & 46.1 & 15.8 & $7.3^{*}$ & 36.4 & 13.0 & 45.1 & 14.6 & -8.75 & 11.88 & $6.6^{*}$ & 43.0 & 15.9 & 46.8 & 16.7 & -3.77 & 9.77 & $3.9^{*}$ \\
\hline $\begin{array}{l}\text { Existential Well- } \\
\text { Being }\end{array}$ & 43.2 & 9.9 & 53.0 & 9.5 & $11.6^{*}$ & 37.6 & 9.4 & 50.9 & 11.0 & -13.31 & 13.03 & $9.1^{*}$ & 47.4 & 7.9 & 54.6 & 7.9 & -7.25 & 9.57 & $7.8^{*}$ \\
\hline $\begin{array}{l}\text { Connectedness } \\
\text { to God }\end{array}$ & 18.2 & 8.7 & 25.4 & 9.3 & $13.4^{*}$ & 15.6 & 7.7 & 24.8 & 8.6 & -9.16 & 8.02 & $10.2^{*}$ & 20.2 & 8.9 & 25.9 & 9.7 & -5.63 & 6.21 & $9.2^{*}$ \\
\hline $\begin{array}{l}\text { Connectedness } \\
\text { to Others }\end{array}$ & 17.1 & 7.8 & 24.8 & 8.8 & $13.2^{*}$ & 13.9 & 6.8 & 23.3 & 8.5 & -9.39 & 8.93 & $9.3^{*}$ & 19.6 & 7.7 & 26.1 & 8.8 & -6.36 & 6.43 & $9.8^{*}$ \\
\hline \multicolumn{20}{|l|}{$\begin{array}{l}\text { Spiritual and } \\
\text { Religious }\end{array}$} \\
\hline $\begin{array}{l}\text { Functioning- } \\
\text { Related } \\
\text { Behaviors }\end{array}$ & 17.3 & 8.5 & 24.8 & 10.2 & $15.3^{*}$ & 14.1 & 7.4 & 23.2 & 10.2 & -9.11 & 7.67 & $10.6^{*}$ & 19.7 & 8.5 & 26.0 & 10.1 & -6.26 & 5.47 & $11.7^{*}$ \\
\hline
\end{tabular}

Note: The $t$ tests compare current and ideal scores.

$* p<.001$.

Table 2

Spiritual and Religious Functioning Scores of Problem Drinkers and Controls

\begin{tabular}{|c|c|c|c|c|c|c|c|c|c|c|c|c|c|c|c|c|c|c|c|}
\hline \multirow[b]{3}{*}{ Scale } & \multicolumn{5}{|c|}{ All participants } & \multicolumn{7}{|c|}{ Problem drinkers } & \multicolumn{7}{|c|}{ Controls } \\
\hline & \multicolumn{2}{|c|}{ Current } & \multicolumn{2}{|c|}{ Ideal } & \multirow[b]{2}{*}{$t(185)$} & \multicolumn{2}{|c|}{ Current } & \multicolumn{2}{|c|}{ Ideal } & \multicolumn{2}{|c|}{ Discrepancy } & \multirow[b]{2}{*}{$t(79)$} & \multicolumn{2}{|c|}{ Current } & \multicolumn{2}{|c|}{ Ideal } & \multicolumn{2}{|c|}{ Discrepancy } & \multirow[b]{2}{*}{$t(105)$} \\
\hline & $M$ & $S D$ & $M$ & $S D$ & & $M$ & $S D$ & $M$ & $S D$ & $M$ & $S D$ & & $M$ & $S D$ & $M$ & $S D$ & $M$ & $S D$ & \\
\hline s Wel & 40.2 & 15.1 & 46.1 & 15.8 & $7.3^{\circ}$ & 36.4 & 13.0 & 45.1 & 14.6 & -8.75 & 11.88 & $6.6^{\circ}$ & 43.0 & 15.9 & 46.8 & 16.7 & -3.77 & 9.7 & $3.9^{\circ}$ \\
\hline Existential Well-Bc & 43.2 & 9.9 & 53.0 & 9.5 & $11.6^{*}$ & 37.6 & 9.4 & 50.9 & 11.0 & -13.31 & 13.03 & $9.1^{\circ}$ & 47.4 & 7.9 & 54.6 & 7.9 & -7.25 & 9.57 & $7.8^{\circ}$ \\
\hline Connectedness to $\mathrm{G}$ & 18.2 & 8.7 & 25.4 & 9.3 & $13.4^{\circ}$ & 15.6 & 7.7 & 24.8 & 8.6 & -9.16 & 8.02 & $10.2^{*}$ & 20.2 & 8.9 & 25.9 & 9.7 & -5.63 & 6.21 & $9.2^{\circ}$ \\
\hline Connectedness to Others & 17.1 & 7.8 & 24.8 & 8.8 & $13.2^{*}$ & 13.9 & 6.8 & 23.3 & 8.5 & -9.39 & 8.93 & $9.3^{\circ}$ & 19.6 & 7.7 & 26.1 & 8.8 & -6.36 & 6.43 & $9.8^{\circ}$ \\
\hline $\begin{array}{l}\text { Spiritual and Religious } \\
\text { Functioning-Related }\end{array}$ & & & & & & & & & & & & & & & & & & & \\
\hline Behaviors & 17.3 & 8.5 & 24.8 & 10.2 & $15.3^{\circ}$ & 14.1 & 7.4 & 23.2 & 10.2 & -9.11 & 7.67 & $10.6^{\circ}$ & 19.7 & 8.5 & 26.0 & 10.1 & -6.26 & 5.47 & $11.7^{\circ}$ \\
\hline
\end{tabular}

Note. The $t$ tests compare current and ideal scores.

${ }_{p}<.001$.

\section{Current and Ideal SRF-DS Scores: Problem Drinkers Versus Controls}

Independent-samples $t$ tests were conducted to compare scores obtained by problem drinkers versus controls on the SRF-DS (see Table 2). As predicted, controls obtained significantly higher scores than problem drinkers on all five SRF-DS current scales: RWB, $t(180.69)=3.07$; EWB, $t(184)=7.66 ; C G, t(183)=3.69 ; C O, t(178)=5.15$; and SRFB, $t(183)=4.74 ;$ all $p s<.0033$.

With respect to ideal SRF-DS scores (see Table 2), results indicated that controls obtained higher scores on all of the scales, but the differences were not statistically significant after the Bonferroni correction (for nondirectional hypothesis testing, alpha was set at .0033): RWB, $t(183)=0.69, p=.49$; $\mathrm{EWB}, t(137.50)=2.57, p=$ $.01 ; \mathrm{CO}, t(176)=2.11, p=.04 ; \mathrm{CG}, t(182)=0.86, p=.39 ;$ and SRFB, $t(183)=1.85, p=.07$.

\section{Discrepancy Scores: Problem Drinkers Versus Controls}

Discrepancy scores were calculated as the difference between each participants' current and ideal scores on each of the five SRF-DS, and these are also displayed in Table 2. One-tailed $t$ tests were conducted, and the discrepancy scores of problem drinkers were significantly greater than those of controls on four of the five scales (equal variances not assumed): RWB, $t(148.73)=3.03, p<.01 ; \mathrm{EWB}, t(139.02)=3.51, p<.01 ; \mathrm{CG}$, $t(145.03)=3.26, p<.01$; and SRFB, $t(136.58)=2.83, p<.01$. The difference between groups in discrepancy scores on the CO scale was not significant, $t(134.96)=2.53, p=.01$.

\section{Discussion}

Clinicians and researchers endeavor to understand the role of spiritual and religious functioning in the development and treatment of alcohol-related problems. Although there has been a convergence of research suggesting that spirituality and religiousness play an important role in alcohol misuse, uncertainty about the implications of the findings endures because of problems with the conceptualization and measurement of the constructs (Lee \& Newberg, 2005; Levin, 1994). In this study, we developed a method for evaluating SRF that 
explicitly acknowledges that a person's rating of the adequacy of SRF can only be compared with his or her own standards. This method of rating "discrepancy" was designed to be as simple and straightforward as possible, as participants are simply asked to rate their current versus their preferred states. For clinicians, this approach might thus be appropriate as a screening evaluation (e.g., to determine whether spirituality or religiousness is a topic worth pursuing).

The first study suggests that the items of the SRF-DS are internally consistent and that the scales have adequate test-retest reliability. The findings of the second study are generally consistent with prior research, supporting the scales' validity. Consistent with research suggesting that alcohol misuse is associated with problems in spiritual and religious concerns, participants with problems of alcohol misuse reported greater discrepancies between their current and ideal SRF. These findings are unique and important, however, as they demonstrate that problem drinkers report relatively substantial problems with SRF in contrast to their own preference (vs. in contrast to nonproblem drinkers).

This study also suggests, however, that most persons may endorse some discrepancy between current and ideal SRF. All participants, regardless of alcohol misuse status, reported that their current spiritual and religious functioning was significantly less than what they would prefer. This is an important finding, suggesting that the comparatively poor SRF of persons who misuse alcohol is a relative but not a unique phenomenon. The study's methodology also points to potential experimental manipulations of spiritual functioning, such that the causal association between improved SRF and alcohol misuse might be evaluated. To be specific, motivational interventions designed to increase the awareness of discrepancy between ideal and current states have been shown to increase the desire to reduce that discrepancy and, thereby, to enhance efforts to change (Hettema, Steele, \& Miller, 2005). Improvements in SRF might likewise be measured as decreased discrepancy between ideal and current functioning, and such improvements might or might not be subsequently associated with improved alcohol problems.

The present study has several aspects that might limit the generalizability of these results. Both the problem drinkers and the controls were nonrandom samples. The former were recruited from an outpatient treatment center, whereas the latter were adult volunteers randomly selected from a college directory. Whether most persons with problems associated with alcohol misuse would report discrepancies between current and ideal functioning remains to be determined. Likewise, it might be that these problem drinkers had been recently trained (via treatment, however brief) to report that their spiritual lives were inadequate. Finally, the gender difference between problem drinkers and controls might explain differences in SRF-DS scores. The validity of this measure of SRF needs to be further established. The findings resulting from the measure are consistent with prior research, suggesting it has both concurrent and criterion-related validity, but its construct validity may be called into question by those that disagree with the current conceptualization of spirituality and religiousness and associated functioning.

This study adds further credence to the accumulating evidence that SRF is related to the development (and potential resolution) of alcohol use problems. A variety of theories have been proposed across numerous disciplines, but the causal mechanism needs to be established.

\section{References}

Albrecht, S. L., Amey, C. H., \& Miller, M. K. (1996). Racial differences in adolescent drug use: The impact of religion. Substance Use and Misuse, 31, 1311-1332.

Bufford, R. K., Paloutzian, R. F., \& Ellison, C. W. (1991). Norms for the spiritual well-being scale. Journal of Psychology and Theology, 19, 56-70.

Chatters, L. M. (2000). Religion and health: Public health and practice. Annual Review of Public Health, 21, 335367. 
Ellison, C. G., \& Smith, J. (1991). Toward an integrative measure of health and well-being. Journal of Psychology and Theology, 19, 35-48.

Emrick, C. D., Tonigan, J. S., Montgomery, H., \& Little, L. (1993). Alcoholics Anonymous: What is currently known? In B. S.McCrady \& W. R.Miller (Eds.), Research on Alcoholics Anonymous: Opportunities and alternatives (pp. 41-76). New Brunswick, NJ: Rutgers Center of Alcohol Studies.

Engs, R. C., Hanson, D. J., \& Diebold, B. A. (1996). The drinking patterns and problems of a national sample of college students. Journal of Alcohol and Drug Education, 41, 13-33.

Fetzer Institute. (1999). Multidimensional measurement of religiousness/spirituality for use in health research. Kalamazoo, MI: Author.

Gorsuch, R. L. (1993). Assessing spiritual values in Alcoholics Anonymous research. In B. S.McCrady \& W. R.Miller (Eds.), Research on Alcoholics Anonymous: Opportunities and alternatives (pp. 301-318). New Brunswick, NJ: Rutgers Center of Alcohol Studies.

Hardesty, P. H., \& Kirby, K. M. (1995). Relation between family religiousness and drug use within adolescent peer groups. Journal of Social Behavior and Personality, 10, 421-430.

Hettema, J., Steele, J., \& Miller, W. R. (2005). Motivational interviewing. Annual Review of Clinical Psychology, 1, 91-111.

Hill, P. C., \& Pargament, K. I. (2003). Advances in the conceptualization and measurement of religion and spirituality: Implications of physical and mental health research. American Psychologist, 58, 64-74.

Idler, E. L., Musick, M. A., Ellison, C. G., George, L. K., Krause, N., Ory, M. G., et al. (2003). Measuring multiple dimensions of religion and spirituality for health research. Research on Aging, 25, 327-365.

Kaskutas, L. A., Turk, N., Bond, J., \& Weisner, C. (2003). The role of religion, spirituality and Alcoholics Anonymous in sustained sobriety. Alcoholism Treatment Quarterly, 21, 1-16.

Kendler, K. S., Gardner, C. O., \& Prescott, C. A. (1997). Religion, psychopathology, and substance use and abuse: A multimeasure, genetic-epidemiologic study. American Journal of Psychiatry, 154, 322-329.

Krause, N. (1999). Religious support. In Fetzer Institute \& National Institute on Aging Work Group (Eds.), Multidimensional measurement of religiousness/spirituality for use in health research (pp. 57-63). Kalamazoo, MI: Fetzer Institute.

Lee, B. Y., \& Newberg, A. B. (2005). Religion and health: A review and critical analysis. Zygon: Journal of Religion \& Science, 40, 443-468.

Levin, J. S. (1994). Religion and health: Is there an association, is it valid, and is it causal?Social Science \& Medicine, 38, 1475-1482.

Miller, W. R. (1997). Spiritual aspects of addictions treatment and research. Mind/Body Medicine: A Journal of Clinical Behavioral Medicine, 2, 37-43.

Miller, W. R. (Ed.). (1999). Integrating spirituality into treatment: Resources for practitioners. Washington, DC: American Psychological Association.

Miller, W. R., \& Thoresen, C. E. (2003). Spirituality, religion, and health: An emerging research field. American Psychologist, 58, 24-35.

Montgomery, H. A., Miller, W. R., \& Tonigan, J. S. (1995). Does Alcoholics Anonymous involvement predict treatment outcome? Journal of Substance Abuse Treatment, 12, 241-246.

Pardini, D. A., Plante, T. G., Sherman, A., \& Stump, J. E. (2000). Religious faith and spirituality in substance abuse recovery: Determining the mental health benefits. Journal of Substance Abuse Treatment, 19, 347-354.

Pargament, K. I., \& Mahoney, A. (2002). Spirituality: The discovery and conservation of the sacred. In C. R.Snyder \& S. J.Lopez (Eds.), Handbook of positive psychology (pp. 646-659). New York: Oxford University Press.

Powell, L. H., Shahabi, L., \& Thoresen, C. E. (2003). Religion and spirituality: Linkages to physical health. American Psychologist, 58, 36-52.

Project MATCH Research Group. (1997). Matching alcoholism treatments to client heterogeneity: Project MATCH posttreatment drinking outcomes. Journal of Studies on Alcohol, 58, 7-29.

Sethi, S., \& Seligman, M. E. P. (1993). Optimism and fundamentalism. Psychological Science, 4, 256-259.

Single, E., Brewster, J. M., MacNeil, P., Hatcher, J., \& Trainor, C. (1995). The 1993 General Social Survey II: Alcohol problems in Canada. Canadian Journal of Public Health, 86, 402-407. 
Underwood, L. G. (1999). Daily spiritual experiences. In Fetzer Institute/National Institute on Aging Work Group (Eds.), Multidimensional measurement of religiousness/spirituality for use in health research (pp. 11-17). Kalamazoo, MI: Fetzer Institute. 